\title{
Prevalence of Hypertension and Obesity among Emirati Patients with Type 2 Diabetes
}

\author{
Bashair M Mussa $^{1 *}$, Yaqeen Abduallah ${ }^{2}$ and Salah Abusnana ${ }^{3}$ \\ ${ }^{1}$ Basic Medical Science Department, College of Medicine, University of Sharjah, Sharjah, P.O.Box: 27272, United Arab Emirates \\ ${ }^{2}$ Faculty of Medicine, McGill University, 3605 Rue de la Montagne, Montréal, QC Canada \\ ${ }^{3}$ Rashid Centre for Diabetes and Research, Ministry of Health, University Street, Al Jurf 2 Area - Ajman, P.O.Box: 21499, United Arab Emirates
}

\begin{abstract}
Introduction: Hypertension and obesity are key risk factors for long-term complications associated with type 2 diabetes mellitus (type $2 \mathrm{DM}$ ). Previous studies have shown that the prevalence of hypertension and obesity is high in the United Arab of Emirates (UAE). However, none of these studies has focused on the investigation of hypertension and obesity in Emirati patients with type 2 DM.

Methodology: The present study is a retrospective observational study which was conducted in Rashid Centre for Diabetes and Research (Ajman, UAE). Medical records for 510 diabetic Emirati patients were examined and 51 medical records were excluded due to incomplete or missing medical data. 459 medical records of Emirati patients with type 2 DM were filtered, examined and analyzed and the following variables were included in the investigation: anthropometric variables, diabetes type and duration, $\mathrm{BMI}, \mathrm{HbA} 1 \mathrm{c}$, blood pressure and lipid profile.

Results and conclusions: Findings of the present study have demonstrated that the prevalence of hypertension and obesity in Emirati patients with type 2 DM were $63 \%$ and $57 \%$, respectively. Compared to non-hypertensive patients, hypertensive patients with type $2 \mathrm{DM}$ were older and had higher levels of $\mathrm{HbA} 1 \mathrm{C}$ and about $60 \%$ of the hypertensive patients were obese. A strong positive relationship between the systolic blood pressure, and age and diabetes duration was observed whereas the diastolic blood pressure was negatively correlated with age and diabetes duration. The prevalence of hypertension and obesity among Emirati patients with type 2 DM was significantly high. Age and diabetes duration have opposite effects on systolic and diastolic blood pressure.
\end{abstract}

Keywords: Emirati patients; Type 2 diabetes mellitus; Obesity; Hypertension

Abbreviations: BMI: Body Mass Index; BP: Blood Pressure; Dbp: Diastolic Blood Pressure; DM: Diabetes Mellitus; Hbalc: Hemoglobin A1c; HDL: High Density Lipoprotein; LDL: Low Density Lipoprotein; RCDR: Rashid Centre for Diabetes and Research; Sbp: Systolic Blood Pressure

\section{Introduction}

Diabetes mellitus (DM) is one of the most challenging health problems in the Gulf countries including the United Arab Emirates (UAE) [1,2]. The latter has experienced a pronounced economic growth during the last decade and this directly and indirectly influenced the lifestyle of Emirati population and led to a considerable increase in the prevalence of several risk factors for chronic disorders such as DM [3]. In 2009, Diabetes International Foundation revealed that five of the gulf countries are among the top ten countries for prevalence of DM with an estimated increase of $93.9 \%$ between 2010 and 2030 [1]. It is noteworthy that the increase in the prevalence of DM is strongly associated with multiple prevalent risk factors including hypertension and obesity [2].

It is well established that hypertension and obesity are major risk factors for cardiovascular disease which is considered as a leading cause of morbidity and mortality in type 2 DM. The relative risk of long-term cardiovascular complications among patients with DM is significantly higher compared to the general population [4-8]. It has been demonstrated that $40 \%$ and $60 \%$ of the patients with DM at age of 45 and 75 , respectively, are hypertensive and about $80 \%$ of type 2 DM patients are overweight or obese [9-11].

Several assumptions were made to explain the pathogenic relationship between hypertension and DM and these include: (i) insulin resistance produces stimulatory effects on the sympathetic nervous system and the renin-angiotensin system and (ii) abnormalities in catecholamines and sodium metabolism [12-14]. On the other hand, lipotoxicity is regarded as the main pathogenic link between obesity and insulin resistance in DM [15].

Previous studies have shown that tight blood pressure (BP) control leads to a considerable reduction in the incidence and progression of long-term vascular complications associated with type $2 \mathrm{DM}$ including stroke, heart failure and death $[9,16,17]$. In addition, it is evident that weight loss contributes greatly in improving insulin resistance and dyslipidemia that associated with type 2 DM [17].

The National Epidemiological Study of Hypertension in the UAE (NESH-UAE) has revealed that hypertension is significantly high among Emirati aged between 30 and 50 years and it seems to be more prevalent among females (54\%) compared to males (47\%). Additionally, a more recent study has reported a high prevalence of hypertension among UAE children and adolescents and emphasized

*Corresponding author: Bashair M Mussa, Basic Medical Science Department College of Medicine, University of Sharjah, Sharjah, P.O.Box: 27272, United Arab Emirates, Tel: +971-65057220; Fax: +971-6558579; E-mail: bmussa@sharjah.ac.ae

Received December 28, 2015; Accepted January 11, 2016; Published January 15,2016

Citation: Mussa BM, Abduallah Y, Abusnana S (2016) Prevalence of Hypertension and Obesity among Emirati Patients with Type 2 Diabetes. J Diabetes Metab 7 638. doi:10.4172/2155-6156.1000638

Copyright: (c) 2016 Mussa BM, et al. This is an open-access article distributed under the terms of the Creative Commons Attribution License, which permits unrestricted use, distribution, and reproduction in any medium, provided the original author and source are credited. 
the positive relationship between hypertension and obesity [18]. The prevalence of the latter among this population was $34.8 \%$ (females) and $34.0 \%$ (males) [19]. Furthermore, a study by Al-Maskari et al. was conducted in $\mathrm{Al}$ Ain district in 2004, has demonstrated that the prevalence of macrovascular diseases among persons with DM in the UAE is $29.5 \%$, respectively [20].

These previous findings are important and informative however it also highlights the necessity of conducting further studies to examine and verify the prevalence of hypertension and obesity among Emirati patients with type $2 \mathrm{DM}$. Accordingly, the present study was designed to (i) determine the prevalence of hypertension and obesity among Emirati patients with type $2 \mathrm{DM}$ and (ii) to investigate the relationship between two disorders, if any, in Emirati patients with type 2 DM who attending Rashid Centre for Diabetes and Research (RCDR). The latter is a specialized diabetes center which offers various clinical services to patients with DM in the UAE and it is located in Ajman (one of the seven Emirati states constituting the UAE).

\section{Methodology}

\section{Subjects and setting}

The present study is a retrospective cross-sectional study which was conducted in RCDR between June 2014 and September 2014. All the subjects of the study were Emirati with type 2 DM ( $>18$ years old) who attending RCDR diabetes clinic in a quarterly basis (initial visit and three follow up visits per annum).

Medical records of 510 Emirati patients with DM were randomly selected from Diamond, an electronic medical records database, which includes 3214 medical records of patients with DM (June 2010-June 2014). All these medical records were created, monitored and updated by RCDR consultant diabologists.

51 medical records were excluded for the following reasons: (i) incomplete or missing data, (ii) medical records of type $1 \mathrm{DM}$ patients and (iii) medical records of patients aged less than 18 years old. 459 medical records of Emirati patients with type $2 \mathrm{DM}$ were examined and analyzed and the following variables were included in the investigation: age (years), gender (male/female), age at diagnosis (years), DM duration (years), body mass index (BMI, $\mathrm{kg} / \mathrm{m}^{2}$ ), systolic blood pressure (sBP, $\mathrm{mmHg}$ ), diastolic blood pressure ( $\mathrm{dBP}, \mathrm{mmHg}$ ), hemoglobin A1c (HbA1C, \%), total cholesterol ( $\mathrm{mmol} / \mathrm{l})$, triglycerides $(\mathrm{mmol} / \mathrm{l})$, high densitylipoprotein (HDL, $\mathrm{mmol} / \mathrm{l})$ and low density lipoprotein (LDL, mmol/l).

The presence of hypertension was determined based on diagnosis by RCDR consultant diabologists ( $\mathrm{BP} \geq 130 / 80 \mathrm{mmHg}$ ) at the initial visit and or use of antihypertensive medications and obesity was defined as $\mathrm{BMI} \geq 30 \mathrm{Kg} / \mathrm{m}^{2}$. After hypertension and obesity were identified in this sample, the study subjects were divided into six groups: (i) hypertensive, (ii) normotensive, (iii) obese, (v) non-obese, (vi) hypertensive and obese, and (vii) normotensive and non-obese. Several comparisons and assessments of the above-mentioned variables were performed within these six groups.

\section{Statistical analysis}

All data are expressed as the means $( \pm$ SD) and counts (percentage) for continuous and discrete variables, respectively. Independent two sided $t$ test was used to compare discrete variables of different groups and the association between $\mathrm{sBP}$ and $\mathrm{dBP}$ and the above-mentioned variables was determined using Pearson's correlation coefficient. Twotailed $p$ value less than 0.05 was considered statistically significant.

\section{Results}

A total number of 459 Emirati patients with type 2 DM were included in the study. As shown in Table 1, the mean age of the studied population was 55.6 years with $59 \%$ female patients. The average age at diagnosis and DM duration were 43.9 years-old and 11.31 years, respectively. In addition, $\mathrm{BMI}, \mathrm{HbA1C}$ and the mean blood pressure of these patients were $32.1 \mathrm{~kg} / \mathrm{m}^{2}, 8.9 \%$ and $136 / 73 \mathrm{mmHg}$, respectively.

The findings of the present study have shown that $63 \%$ of the Emirati patients with type $2 \mathrm{DM}$ are hypertensive $(\mathrm{sBP}, 143.1 \pm 22.7 \mathrm{mmHg}$ and $\mathrm{dBP}, 74.3 \pm 11.2 \mathrm{mmHg}$ ). Compared to normotensive patients, hypertensive patients were older ( $59.6 \pm 11.4$ years), had longer duration of DM (12.8 \pm 7.6 years) and the mean of age at DM diagnosis was significantly higher $(P<0.0001)$ in patients with hypertension (Table 2$)$. In addition, $\mathrm{HbA} 1 \mathrm{c}$ level $(9.0 \pm 2.0 \%)$ was significantly higher $(P<0.05)$ among hypertensive patients compared to normotensive patients. BMI $\left(32.3 \pm 7.0 \mathrm{~kg} / \mathrm{m}^{2}\right)$ was slightly higher among hypertensive patients and about $60 \%$ of the hypertensive patients with type 2 DM were obese. There was no significant difference in the lipid profile (total cholesterol, triglycerides, HDL and LDL) between the two groups (Table 2).

The prevalence of obesity among the studied population was $57 \%$. Obese Emirati patients with type $2 \mathrm{DM}$ were significantly younger (52.7 \pm 12.6 years, $P<0.0001)$ compared to non-obese patients (Table 3). In addition, obese patients had significantly shorter duration of DM $(P<0.05)$ compared to non-obese patients. On the other hand, HbAlc

\begin{tabular}{|c|c|}
\hline Variables & \\
\hline Subjects $(n)$ & 459 \\
\hline Age (years) & $55.6 \pm 12.9$ \\
\hline Gender & $188(41)$ \\
Male, $n(\%)$ & $271(59)$ \\
\hline Female, $n(\%)$ & $32.1 \pm 12.2$ \\
\hline BMl (kg/m $\left.{ }^{2}\right)$ & $43.9 \pm 12.5$ \\
\hline Age at diagnosis (years) & $11.3 \pm 7.6$ \\
\hline Diabetes duration (years) & $8.9 \pm 2.0$ \\
\hline HbA1c (\%) & $136.8 \pm 21.7$ \\
\hline sBP & $73.3 \pm 10.6$ \\
\hline dBP & \\
\hline
\end{tabular}

Data are expressed as means \pm SD for continuous variables and as counts (percentage) for categorical variables

Table 1: Demographic and clinical profile of the studied population.

\begin{tabular}{|c|c|c|c|}
\hline Variables & Hypertensive & Normotensive & $p$ Value \\
\hline$n(\%)$ & $287(63)$ & $172(37 \%)$ & - \\
\hline Age (years) & $59.6 \pm 11.4$ & $48.9 \pm 12.5$ & $<0.0001$ \\
\hline Gender, Female, $n(\%)$ & $176(61)$ & $95(55)$ & - \\
\hline BMl $\left(\mathrm{kg} / \mathrm{m}^{2}\right)$ & $32.3 \pm 7.0$ & $31.6 \pm 6.1$ & $>0.05$ \\
\hline $30\left(\mathrm{~kg} / \mathrm{m}^{2}\right), n(\%)$ & $174(60)$ & $97(45)$ & - \\
\hline Age at diagnosis (years) & $46.4 \pm 12.3$ & $39.7 \pm 11.9$ & $<0.0001$ \\
\hline Diabetes Duration (years) & $12.8 \pm 7.6$ & $8.9 \pm 6.9$ & $<0.0001$ \\
\hline Systolic BP $(\mathrm{mmHg})$ & $143.1 \pm 22.7$ & $126.0 \pm 14.5$ & $<0.001$ \\
\hline Diastolic BP $(\mathrm{mmHg})$ & $74.3 \pm 11.2$ & $71.6 \pm 9.2$ & $<0.05$ \\
\hline HbA1C $(\%)$ & $9.0 \pm 2.0$ & $8.5 \pm 1.8$ & $<0.05$ \\
\hline Total Cholesterol $(\mathrm{mmol} / \mathrm{l})$ & $4.6 \pm 1.2$ & $4.7 \pm 1.1$ & $>0.05$ \\
\hline Triglycerides $(\mathrm{mmol} / \mathrm{l})$ & $1.9 \pm 1.8$ & $1.7 \pm 1.4$ & $>0.05$ \\
\hline HDL $(\mathrm{mmol} / \mathrm{l})$ & $1.2 \pm 0.3$ & $1.3 \pm 2.1$ & $>0.05$ \\
\hline LDL $(\mathrm{mmol} / \mathrm{l})$ & $2.8 \pm 1.0$ & $3.0 \pm 0.9$ & $>0.05$ \\
\hline
\end{tabular}

Data are expressed as means \pm SD for continuous variables and as counts (percentage) for categorical variables

Table 2: Demographic and clinical data of hypertensive vs normotensive patients with type 2 diabetes mellitus. 


\begin{tabular}{|c|c|c|c|}
\hline Variables & Obese & Non-obese & $\boldsymbol{p}$ Value \\
\hline$n(\%)$ & $261(57)$ & $199(43)$ & - \\
\hline Age (years) & $52.7 \pm 12.6$ & $59.5 \pm 12.1$ & $<0.0001$ \\
\hline Gender, Female, $n(\%)$ & $170(65)$ & $102(51)$ & - \\
\hline BMI $\left(\mathrm{kg} / \mathrm{m}^{2}\right)$ & $36.4 \pm 5.5$ & $26.3 \pm 2.5$ & $<0.0001$ \\
\hline Age at diagnosis (years) & $41.6 \pm 12.1$ & $35.1 \pm 21.1$ & $<0.0001$ \\
\hline Diabetes Duration (years) & $10.6 \pm 7.5$ & $12.3 \pm 7.7$ & $<0.05$ \\
\hline Systolic BP $(\mathrm{mmHg})$ & $135.7 \pm 21.2$ & $138.3 \pm 22.1$ & $>0.05$ \\
\hline Diastolic BP $(\mathrm{mmHg})$ & $73.2 \pm 10.4$ & $73.4 \pm 10.8$ & $>0.05$ \\
\hline HbA1C $(\%)$ & $9.0 \pm 2.1$ & $8.7 \pm 1.9$ & $>0.05$ \\
\hline Total Cholesterol $(\mathrm{mmol} / \mathrm{l})$ & $4.6 \pm 2.1$ & $4.6 \pm 1.2$ & $>0.05$ \\
\hline Triglycerides $(\mathrm{mmo} / \mathrm{l})$ & $1.8 \pm 1.8$ & $1.8 \pm 1.6$ & $>0.05$ \\
\hline HDL $(\mathrm{mmol} / \mathrm{l})$ & $1.2 \pm 1.7$ & $1.2 \pm 0.3$ & $>0.05$ \\
\hline LDL (mmol/l) & $2.9 \pm 0.9$ & $2.9 \pm 1.1$ & $>0.05$ \\
\hline
\end{tabular}

Data are expressed as means \pm SD for continuous variables and as counts (percentage) for categorical variables

Table 3: Demographic and clinical data of obese vs non-obese patients with type 2 diabetes mellitus.

was slightly higher among obese patients however no significant differences were observed in the BP and lipid profile (total cholesterol, triglycerides, HDL and LDL) between the obese and non-obese patients (Table 3).

As shown in Table 4, hypertensive and obese patients were significantly older $(57.0 \pm 11.3$ years, $P<0.05)$ with longer duration (12.6 \pm 7.7 years) of $\mathrm{DM}$ and the mean age at diagnosis $(43.9 \pm 11.7$ years) was higher compared to normotensive and non-obese patients.

A strong positive relationship between the sBP and age $(r=0.307$, $P<0.0001)$ and DM duration $(r=0.095, P<0.05)$ was observed. On the other hand, $\mathrm{dBP}$ was negatively correlated with age $(r=-0.120, P<0.05)$ and DM duration $(r=-0.200, P<0.0001)$ (Table 5).

\section{Discussion}

There is unequivocal evidence that determination of the prevalence of DM risk factors such as hypertension and obesity in Emirati population is a very essential measure for creating and designing DM specialized care and management plans. For the first time, the present study investigated and determined the prevalence of hypertension and obesity among Emirati patients with type 2 DM in the Northern Emirates of the UAE. The present study has reported a high prevalence (63\%) of hypertension among Emirati patients with type $2 \mathrm{DM}$ attending RCDR. Age is considered as a key factor for development of hypertension in these patients.

In agreement with these findings, a study by Arifulla et al. has demonstrated that about $80 \%$ of the patients attending a tertiary care hospital in Ajman have hypertension which is strongly correlated with age and DM duration [21]. On the other hand, an investigation of macrovascular complications among patients with DM in Al-Ain district has shown that $35 \%$ of the population had hypertension. This variation in the prevalence of hypertension in the UAE could be due to several differences between the present study and the previous studies including: (i) the sample size (ii) the study design and (iii) the nationality of the study participants. The UAE is well known as one of the most ethnically diverse countries where $80 \%$ of the population is of non-Emirati origin [22,23]. Previous studies have included all the nationalities in the UAE whereas the present study only included Emirati citizen with type 2 DM. Several observations (unpublished data) have suggested that there are differences between Emirati population and other populations in the UAE and this includes the lifestyle and the genetic background. Additionally, in the present study the diagnosis of DM was confirmed by consultant diabologists.

A substantial amount of the literature has demonstrated that prevalence of hypertension in type $2 \mathrm{DM}$ patients varies across different ethnic and racial groups. In Asia, the highest prevalence of hypertension in patients with type $2 \mathrm{DM}$ was $85.8 \%$ and $60.2 \%$ at BP thresholds of $130 / 80 \mathrm{mmHg}$ and $140 / 90 \mathrm{mmHg}$, respectively and the lowest prevalence of hypertension in persons with DM was $40.4 \%$ at BP threshold of $140 / 90 \mathrm{mmHg}[24,25]$. Similarly, the highest and the lowest prevalence of hypertension in type $2 \mathrm{DM}$ among Africans were $80 \%$ and $38.5 \%$, respectively [26].

On the other hand, several reports have shown that hypertension is very prevalent among Europeans with DM and the highest and the lowest rates were $95 \%$ and $29.3 \%$, respectively [27-29]. In USA, $70.9 \%$ was the highest prevalence of hypertension among type $2 \mathrm{DM}$ patients and the lowest prevalence reported was $66.9 \%$ [30]. Taking into account the previous and the present findings, it seems that hypertension affects more than $60 \%$ of the patients with type $2 \mathrm{DM}$, globally.

Emirati hypertensive patients with type $2 \mathrm{DM}$ have higher $\mathrm{HbA1c}$ levels compared to normotensive patients however no significant differences were observed in the lipid profile of these two groups. It is noteworthy that normotensive Emirati patients are obese suggesting

\begin{tabular}{|c|c|c|c|}
\hline Variables & $\begin{array}{c}\text { Hypertensive } \\
\text { and Obese }\end{array}$ & $\begin{array}{c}\text { Normotensive } \\
\text { and Non-obese }\end{array}$ & p Value \\
\hline$n(\%)$ & $163(36)$ & $76(17)$ & - \\
\hline Age (years) & $57.0 \pm 11.3$ & $53.6 \pm 12.3$ & $<0.05$ \\
\hline Gender, Female, $n(\%)$ & $107(65)$ & $33(43)$ & - \\
\hline BMl (kg/m $)$ & $36.8 \pm 5.8$ & $26.2 \pm 2.3$ & $<0.0001$ \\
\hline Age at diagnosis (years) & $43.9 \pm 11.7$ & $42.2 \pm 11.2$ & $<0.05$ \\
\hline Diabetes Duration (years) & $12.6 \pm 7.7$ & $10.7 \pm 7.9$ & $>0.05$ \\
\hline Systolic BP (mmHg) & $141.9 \pm 22.4$ & $126.9 \pm 14.9$ & $<0.0001$ \\
\hline Diastolic BP (mmHg) & $74.0 \pm 10.9$ & $71.1 \pm 8.9$ & $<0.05$ \\
\hline HbA1C (\%) & $9.3 \pm 2.1$ & $8.7 \pm 1.8$ & $<0.05$ \\
\hline Total Cholesterol (mmol/l) & $4.6 \pm 1.2$ & $4.7 \pm 1.3$ & $>0.05$ \\
\hline Triglycerides (mmol/l) & $1.8 \pm 1.9$ & $1.7 \pm 1.4$ & $>0.05$ \\
\hline HDL (mmol/l) & $1.1 \pm 0.3$ & $1.7 \pm 0.3$ & $>0.05$ \\
\hline LDL (mmol/l) & $2.8 \pm 1.0$ & $3.0 \pm 1.1$ & $>0.05$ \\
\hline
\end{tabular}

Data are expressed as means \pm SD for continuous variables and as counts (percentage) for categorical variables

Table 4: Demographic and clinical data of hypertensive and obese vs normotensive and non-obese patients with type 2 diabetes mellitus.

\begin{tabular}{|c|c|c|c|c|}
\hline & \multicolumn{2}{|c|}{ sBP } & \multicolumn{2}{c|}{ dBP } \\
\hline Variables & $R$ & $P$ value & $r$ & $P$ value \\
\hline Age & 0.307 & $<0.0001$ & -0.120 & $<0.001$ \\
\hline BMI $\left(\mathrm{kg} / \mathrm{m}^{2}\right)$ & 0.006 & $>0.05$ & -0.057 & $>0.05$ \\
\hline Age at diagnosis (years) & 0.285 & $>0.0001$ & 0.008 & $>0.05$ \\
\hline Diabetes duration (years) & 0.095 & $<0.05$ & -0.200 & $<0.0001$ \\
\hline HbA1c $(\%)$ & 0.067 & $>0.05$ & 0.059 & $>0.05$ \\
\hline Total Cholesterol (mmol/l) & 0.006 & $>0.05$ & 0.087 & $>0.05$ \\
\hline Triglycerides $(\mathrm{mmol} / \mathrm{l})$ & 0.009 & $>0.05$ & 0.066 & $>0.05$ \\
\hline HDL $(\mathrm{mg} / \mathrm{dL})(\mathrm{mmol} / \mathrm{l})$ & 0.063 & $>0.05$ & 0.066 & $>0.05$ \\
\hline LDL $(\mathrm{mg} / \mathrm{dL})(\mathrm{mmol} / \mathrm{l})$ & -0.005 & $>0.05$ & -0.081 & $>0.05$ \\
\hline
\end{tabular}

DBP: Diastolic Blood Pressure; R: Pearson's Correlation Coefficient; SBP: Systolic Blood Pressure

Table 5: Association between demographic and clinical variables and systolic and diastolic blood pressure. 
that obesity is not directly related to hypertension in these group of patients.

The present study has also revealed that the $60 \%$ of the hypertensive Emirati patients with type $2 \mathrm{DM}$ were obese whereas the prevalence of obesity among normotensive patients was $45 \%$. In contrast, a national multicentre study in Brazil has reported that $40.5 \%$ of the hypertensive type $1 \mathrm{DM}$ patients with mean age of 30.5 years were obese or overweight whereas a lower incidence $(29.2 \%)$ of obesity was observed among normotensive patients [31]. The mean age of the study population and the type of DM clearly explain the differences in the prevalence rate of obesity among hypertensive DM patients in the latter and the present study. Comparatively, results from Swedish National Diabetes Register have demonstrated that the prevalence of hypertension among type 2 $\mathrm{DM}$ varies based on the values of BMI. The prevalence of hypertension among normal weight $\left(\mathrm{BMI}<25 \mathrm{~kg} / \mathrm{m}^{2}\right)$, overweight (BMI 25-29.9 $\mathrm{kg} /$ $\left.\mathrm{m}^{2}\right)$ and obese $\left(\mathrm{BMI} \geq 30 \mathrm{~kg} / \mathrm{m}^{2}\right)$ patients with DM was $76.6 \%, 83.4 \%$ and $87.5 \%$, respectively [11].

Several lines of evidence suggested that obesity has a dramatic influence on the development of type $2 \mathrm{DM}$ vascular complications [32]. International studies have shown that the prevalence of obesity among DM patients is more than $30 \%$ supporting the findings of the present study which revealed that the prevalence of obesity among Emirati patients with type $2 \mathrm{DM}$ is $57 \%$. Similar prevalence rates of obesity among patients with type 2DM were reported in Qatar and Jordan, $53.5 \%$ and $58.6 \%$, respectively $[33,34]$. However, it seems that the highest prevalence of obesity in the world was reported in the Middle East particularly in Iran and Sauid Arabia, 85.5\% and 83.45\%, respectively $[35,36]$.

One of the interesting findings of the present study is that Emirati obese patients with type $2 \mathrm{DM}$ were significantly younger than the nonobese patients. In addition, there were no significant differences in BP and lipid profile between the obese and non-obese patients. Given that the BMI value of the latter is $26.3 \mathrm{~kg} / \mathrm{m}^{2}$ (considered overweight) and the mean age of the two groups is above 50 years may provide an appropriate interpretation for these outcomes.

A comparison between the hypertensive obese and normotensive non-obese patients has shown that age is the most important determining factor of hypertension in this group of patients however, DM duration was not significantly different between these two groups of patients. Taking into account this finding along with the previous findings, we can propose that factors other than obesity and DM duration contribute to development of hypertension in Emirati patients with type $2 \mathrm{DM}$ and this may include diverse genetic profiles and lifestyle components. Further studies are required to elaborate on how these factors can act as risk factors for development of hypertension in Emirati patients with type $2 \mathrm{DM}$.

As expected, sBP was significantly higher among hypertensive patients with type $2 \mathrm{DM}$ compared to normotensive patients. There is strong evidence for the positive effect of lowering blood pressure on the microvascular complications associated with DM and it has been shown that the rate of stroke and death was considerably reduced in patients with BP $144 / 82 \mathrm{mmHg}$ compared to patients with higher BP, $154 / 87 \mathrm{mmHg}[9,37,38]$. Classically, sBP has been viewed as being a stronger predicator of cardiovascular disease and coronary heart disease compared to the $\mathrm{dBP}$, however several reports have also demonstrated that diastolic hypotension as consequential event of antihypertensive therapy is associated with an increased risk of myocardial infarction [39]. Additionally, it has been found that the relative risk of the latter is doubled at $\mathrm{dBP}$ threshold of $60 \mathrm{mmHg}$ compared to $\mathrm{dBP}$ threshold of $100 \mathrm{mmHg}$ [40]. Moreover, ageing seems to have opposed effects on sBP and $\mathrm{dBP}$ and this hypothesis is supported by the findings of the present study which indicated that sBP was positively correlated with the age and DM duration whereas a negative association was found between $\mathrm{dBP}$, and age and DM duration. Other reports have emphasized the effects of aging on $\mathrm{dBP}$ by showing that the latter increases until the age of 60 years old and then it starts to decline continuously [41,42]. A study by Ronnback et al. has further supported these findings by indicating that sBP of type $1 \mathrm{DM}$ subjects in all age-groups was significantly higher than in subjects without DM, whereas the changes of $\mathrm{dBP}$ were age-dependent, younger subjects $(<40$ years old) and older subjects ( $>45$ years old) had higher and lower dBP, respectively [43]. Similarly, in type $2 \mathrm{DM}$ a consistent increase in sBP with age was reported however dBP failed to gradually increase with age [24]. In the light of the above-mentioned findings, it is reasonable to suggest that guidelines for $\mathrm{BP}$ control in patients with $\mathrm{DM}$ should include minimal $\mathrm{dBP}$ rate target and elderly patients with long duration of DM should maintain $\mathrm{dBP}>70 \mathrm{mmHg}$ to avoid the cardiovascular morbidity and mortality associated with diastolic hypotension. Whether the beneficial effects of avoiding the latter are more important than maintaining sBP $<130 \mathrm{mmHg}$ in DM remains to be a debatable question [44].

Although all RCDR hypertensive patients with type $2 \mathrm{DM}$ are taking multiple antihypertensive medications, the mean of the sBP among this population was $143 \mathrm{mmHg}$. This may indicate the presence of resistant hypertension in RCDR type $2 \mathrm{DM}$ patients, therefore further studies need to be conducted to investigate the nature of resistant hypertension and the effects of antihypertensive therapy in this group of patients.

\section{Conclusions}

The prevalence of hypertension among Emirati patients with type $2 \mathrm{DM}$ is considerably high $(63 \%)$ and age is the key factor for the development of hypertension in DM. Prevalence of obesity among the studied population is $57 \%$ and obese patients were significantly younger than non-obese patients. Interestingly, the present study has demonstrated that in Emirati patients with type 2 DM, sBP was increased in age- and DM duration-dependent fashion whereas dBP was negatively correlated with age and DM duration.

\section{Competing Interests}

The authors declare that they have no competing interest.

\section{Acknowledgement}

This work has been supported by Rashid Centre for Diabetes and Research (Ajman, UAE)

\section{References}

1. IDF Diabetes Atlas (2009) $4^{\text {th }}$ edn, Brussels Belgium, International Diabetes Federation.

2. Alhyas L, McKay A, Balasanthiran A, Majeed A (2011) Prevalences of overweight, obesity, hyperglycaemia, hypertension and dyslipidaemia in the Gulf: systematic review. JRSM Short Rep 2: 55.

3. Barakat-Haddad C (2013) Prevalence of high blood pressure, heart disease thalassemia, sickle-cell anemia, and iron-deficiency anemia among the UAE adolescent population. J Environ Public Health doi: 10.1155/2013/680631.

4. Pyörala K, Laakso M, Uusitupa M (1987) Diabetes and atherosclerosis: an epidemiologic view. Diabetes Metab Rev 3: 463-524

5. Steiner G (1981) Diabetes and atherosclerosis: an overview. Diabetes 30: 1-7.

6. Kannel WB, McGee DL (1979) Diabetes and cardiovascular disease. The Framingham study. JAMA 241: 2035-2038. 
Citation: Mussa BM, Abduallah Y, Abusnana S (2016) Prevalence of Hypertension and Obesity among Emirati Patients with Type 2 Diabetes. J Diabetes Metab 7: 638. doi:10.4172/2155-6156.1000638

Page 5 of 5

7. Adler Al, Neil HA, Manley SE, Holman RR, Turner RC (1999) Hyperglycemia and hyperinsulinemia at diagnosis of diabetes and their association with subsequent cardiovascular disease in the United Kingdom prospective diabetes study (UKPDS 47). Am Heart J 138: 353-359.

8. Arauz-Pacheco C, Parrott MA, Raskin P; American Diabetes Association (2003) Treatment of hypertension in adults with diabetes. Diabetes Care 26 Suppl 1: S80-82.

9. UK Prospective Diabetes Study Group (1998) Tight blood pressure control and risk of macrovascular and microvascular complications in type 2 diabetes. BM 17: 703-713.

10. Mugharbel KM, Al-Mansouri MA (2003) Prevalence of obesity among type 2 diabetic patients in Al-khobar primary health care centers. J Family Community Med 10: 49-53

11. Ridderstråle $M$, Gudbjörnsdottir S, Eliasson B, Nilsson PM, Cederholm J Steering Committee of the Swedish National Diabetes Register (NDR) (2006) Obesity and cardiovascular risk factors in type 2 diabetes: results from the Swedish National Diabetes Register. J Intern Med 259: 314-322.

12. Jarrett RJ, Keen H, McCartney M, Fuller JH, Hamilton PJ, et al. (1978) Glucose tolerance and blood pressure in two population samples: their relation to diabetes mellitus and hypertension. Int J Epidemiol 7: 15-24.

13. Cambien F (1982) Relationship between obesity and arterial hypertension Nouv Presse Med 11: 3641-3646.

14. Drury PL (1983) Diabetes and arterial hypertension. Diabetologia 24: 1-9.

15. Day C (2011) Obesity in the Pathogenesis of Type 2 Diabetes. BJDVD 321: 12-419.

16. Adler AI, Stratton IM, Neil HA, Yudkin JS, Matthews DR, et al. (2000) Association of systolic blood pressure with macrovascular and microvascular complications of type 2 diabetes (UKPDS 36 ): prospective observational study. BMJ 321: 412-419.

17. American Diabetes Association (2013) Standards of medical care in diabetes--2013. Diabetes Care 36 Suppl 1: S11-66.

18. Abdulle A, Al-Junaibi A2, Nagelkerke N3 (2014) High blood pressure and its association with body weight among children and adolescents in the United Arab Emirates. PLoS One 9: e85129.

19. Al Junaibi A, Abdulle A, Sabri S, Hag-Ali M, Nagelkerke N (2013) The prevalence and potential determinants of obesity among school children and adolescents in Abu Dhabi, United Arab Emirates. Int J Obes (Lond) 37: 68-74.

20. Al-Maskari F, El-Sadig M, Norman JN (2007) The prevalence of macrovascular complications among diabetic patients in the United Arab Emirates. Cardiovasc Diabetol 6: 24

21. Arifulla M, John LJ, Sreedharan J, Muttappallymyalil J, Basha SA (2014) Patients' Adherence to Anti-Diabetic Medications in a Hospital at Ajman, UAE. Malays J Med Sci 21: 44-49.

22. United Arab Emirates National Bureau of Statistics (2010) http://www uaestatistics.gov.ae.

23. Preliminary Results of Population, Housing and Establishment Census (2006) United Arab Emirates, Ministry of Economy, Abu Dhabi, UAE.

24. Kabakov E, Norymberg C, Osher E, Koffler M, Tordjman K, et al. (2006) Prevalence of hypertension in type 2 diabetes mellitus: impact of the tightening definition of high blood pressure and association with confounding risk factors. J Cardiometab Syndr 1: 95-101.

25. Nakano S, Ito T, Furuya K, Tsuda S, Konishi K, et al. (2004) Ambulatory blood pressure level rather than dipper/nondipper status predicts vascular events in type 2 subjects. Hypertension Res 27: 647-656.

26. Makuyana D, Gomo Z, Munyombwe T, Matenga JA, Hakim JG (2004) Metabolic syndrome disorders in urban black Zimbabweans with type 2 Diabetes mellitus. Cent Afr J Med 50: 24-29.

27. Hassing LB, Hofer SM, Nilsson SE, Berg S, Pedersen NL, et al. (2004)
Comorbid type 2 diabetes mellitus and hypertension exacerbates cognitive decline: evidence from a longitudinal study. Age Ageing 33: 355-361.

28. Nilsson PM, Cederholm J, Zethelius BR, Eliasson BR, Eeg-Olofsson K, et al. (2011) Trends in blood pressure control in patients with type 2 diabetes: data from the Swedish National Diabetes Register (NDR). Blood Press 20: 348-354

29. Koehler C, Ott P, Benke I, Hanefeld M, Group. D (2007) Comparison of the prevalence of the metabolic syndrome by WHO, AHA/NHLBI, and IDF definitions in a German population with type 2 diabetes: the Diabetes in Germany (DIG) Study. Horm Metab Res 39: 632-635.

30. Suh DC, Choi IS, Plauschinat C, Kwon J, Baron M (2010) Impact of comorbid conditions and race/ethnicity on glycemic control among the US population with type 2 diabetes, 1988-1994 to 1999-2004. J Diabetes Complications 24: 382

31. Gomes MB, Tannus LR, Matheus AS, Cobas RA, Palma CC, et al. (2013) Prevalence awareness and treatment of hypertension in patients with type 1 diabetes: a nationwide multicenter study in Brazil. Int J Hypertens doi: $10.1155 / 2013 / 565263$

32. Eeg-Olofsson K, Cederholm J, Nilsson PM, Zethelius B, Nunez L, et al. (2009) Risk of cardiovascular disease and mortality in overweight and obese patients with type 2 diabetes: an observational study in 13,087 patients. Diabetologia 52: $65-73$

33. Bener A, Zirie M, Al-Rikabi A (2005) Genetics, obesity, and environmental risk factors associated with type 2 diabetes. Croat Med J 46: 302-307.

34. Mubarak FM, Froelicher ES, Jaddou HY, Ajlouni KM (2008) Hypertension among 1000 patients with type 2 diabetes attending a national diabetes cente in Jordan. Ann Saudi Med 28: 346-351.

35. Shirafkan A, Marjani A (2011) Prevalence of Obesity Among Type 2 Diabetes Mellitus In Gorgan (South East of Caspian Sea), Iran. World Appl Sci J 14 1389-1396.

36. Alwakeel JS, Sulimani R, Al-Asaad H, Al-Harbi A, Tarif N, et al. (2008) Diabetes complications in 1952 type 2 diabetes mellitus patients managed in a single institution in Saudi Arabia. Ann Saudi Med 28: 260-266.

37. Estacio RO, Jeffers BW, Gifford N, Schrier RW (2000) Effect of blood pressure control on diabetic microvascular complications in patients with hypertension and type 2 diabetes. Diabetes Care 23 Suppl 2: B54-64.

38. Hansson L, Zanchetti A, Carruthers SG, Dahlaf B, Elmfeldt D, et al. (1998) Effects of intensive blood-pressure lowering and low-dose aspirin in patients with hypertension: principal results of the Hypertension Optimal Treatment (HOT) randomised trial. HOT Study Group. Lancet 351: 1755-1762.

39. Benetos A, Thomas F, Bean K, Gautier S, Smulyan H, et al. (2002) Prognostic value of systolic and diastolic blood pressure in treated hypertensive men. Arch Intern Med 162: 577-581.

40. D'Agostino RB, Belanger AJ, Kannel WB, Cruickshank JM (1991) Relation of low diastolic blood pressure to coronary heart disease death in presence of myocardial infarction: the Framingham Study. BMJ 303: 385-389.

41. Burt VL, Cutler JA, Higgins M, Horan MJ, Labarthe D, et al. (1995) Trends in the prevalence, awareness, treatment, and control of hypertension in the adult US population. Data from the health examination surveys, 1960 to 1991. Hypertension 26: 60-90.

42. Franklin SS, Gustin W 4th, Wong ND, Larson MG, Weber MA, et al. (1997) Hemodynamic patterns of age-related changes in blood pressure. The Framingham Heart Study. Circulation 96: 308-315.

43. Rönnback M, Fagerudd J, Forsblom C, Pettersson-Fernholm K, Reunanen A et al. (2004) Altered age-related blood pressure pattern in type 1 diabetes. Circulation 110: 1076-1082.

44. Osher E, Stern N (2008) Diastolic pressure in type 2 diabetes: can target systolic pressure be reached without "diastolic hypotension"? Diabetes Care 31 Suppl 2: S249-254. 